\title{
Glucocorticoid insensitivity as a future target of therapy for chronic obstructive pulmonary disease
}

This article was published in the following Dove Press journal:

International Journal of Chronic Obstructive Pulmonary Disease

31 August 2010

Number of times this article has been viewed

\author{
John A Marwick' \\ Kian Fan Chung ${ }^{2}$ \\ 'Medical Research Council Centre \\ for Inflammation Research, The \\ Queen's Medical Research Institute, \\ University of Edinburgh Medical \\ School, Edinburgh, UK; ${ }^{2}$ Section of \\ Airways Disease, National Heart \\ and Lung Institute, Imperial College \\ London, UK
}

\begin{abstract}
Chronic obstructive pulmonary disease (COPD) is characterized by an abnormal and chronic inflammatory response in the lung that underlies the chronic airflow obstruction of the small airways, the inexorable decline of lung function, and the severity of the disease. The control of this inflammation remains a key strategy for treating the disease; however, there are no current anti-inflammatory treatments that are effective. Although glucocorticoids (GCs) effectively control inflammation in many diseases such as asthma, they are less effective in COPD. The molecular mechanisms that contribute to the development of this relative GC-insensitive inflammation in the lung of patients with COPD remain unclear. However, recent studies have indicated novel mechanisms and possible therapeutic strategies. One of the major mechanisms proposed is an oxidantmediated alteration in the signaling pathways in the inflammatory cells in the lung, which may result in the impairment of repressor proteins used by the GC receptor to inhibit the transcription of proinflammatory genes. Although these studies have described mechanisms and targets by which GC function can be restored in cells from patients with COPD, more work is needed to completely elucidate these and other pathways that may be involved in order to allow for more confident therapeutic targeting. Given the relative GC-insensitive nature of the inflammation in COPD, a combination of therapies in addition to a restoration of GC function, including effective alternative anti-inflammatory targets, antioxidants, and proresolving therapeutic strategies, is likely to provide better targeting and improvement in the management of the disease.
\end{abstract}

Keywords: inflammation, oxidative stress, histone deacetylase, phosphoinositol 3-kinase, p38 mitogen-activated protein kinase

\section{Definition and prevalence}

Chronic obstructive pulmonary disease (COPD) is a disease of the lungs where there is an abnormal chronic inflammatory response. ${ }^{1}$ This is associated with remodeling and narrowing of the small airways, which results in airflow limitation and a gradual inexorable decline of lung function that is not fully reversible and is progressive., . $^{2,3}$ COPD is usually diagnosed in the clinic by a postbronchodilator forced expiratory volume in 1 second (FEV1)/forced vital capacity (FVC) ratio of $<70 \%$ and a FEV1 of $\geq 80 \%$ predicted. ${ }^{3,4}$ According to the Global Initiative for Chronic Obstructive Lung Disease (GOLD) guidelines, COPD severity can be categorized into 4 stages (I-IV) on the basis of FEV1 (Table 1$).{ }^{3}$ COPD is considered a preventable and treatable disease in which there may be some significant extrapulmonary effects that may also contribute to the severity of the disease in individual patients. ${ }^{3}$ 
The abnormal inflammatory response in the lungs of patients with COPD is usually considered to be the result associated with exposure to noxious particles or gases such as those contained in cigarette smoke, which is recognized as the main etiological factor associated with the development of COPD. ${ }^{1,4}$ However, cigarette smoking does not fully explain variations in disease prevalence; therefore, other risk factors are likely to be involved, such as exposure to fossil fuels and environmental traffic pollution. ${ }^{5}$ One of the important features of the disease is that the chronic inflammatory response in the lung often persists even when the main exogenous driving factor such as cigarette smoke has been removed. This apparent self-perpetuation of the chronic inflammatory response may contribute to the continuous decline of lung function and subsequent progression of the disease. ${ }^{1,6,7}$

COPD is a leading cause of morbidity and mortality. Although the incidence of cigarette smoking in the western world is decreasing, as the population ages, the incidence of COPD is likely to increase before decreasing given the latent nature of the disease. Furthermore, cigarette smoking is increasing in densely populated developing nations such as China, which will further enhance the global burden of the disease. The World Health Organization (WHO) estimated that 3 million people died of COPD in 2005, and there were approximately 210 million people with COPD in 2007. ${ }^{8}$ Currently, COPD is the fifth most common cause of mortality worldwide, but total deaths due to the disease are predicted to rise by $30 \%$ in the next 10 years. ${ }^{8}$ COPD is now predicted to become the third leading cause of death worldwide by around $2030 .^{8}$

Table I GOLD stages of chronic obstructive pulmonary disease severity

\begin{tabular}{|c|c|c|}
\hline \multirow{2}{*}{$\begin{array}{l}\text { COPD } \\
\text { severity }\end{array}$} & \multicolumn{2}{|c|}{ Characteristics } \\
\hline & $\begin{array}{l}\text { FEVII } \\
\text { FVC }\end{array}$ & FEVI \\
\hline $\begin{array}{l}\text { GOLD Stage I } \\
\text { (mild) }\end{array}$ & $<70 \%$ & - \\
\hline $\begin{array}{l}\text { GOLD Stage II } \\
\text { (moderate) }\end{array}$ & $<70 \%$ & $<50 \%-70 \%$ \\
\hline $\begin{array}{l}\text { GOLD Stage III } \\
\text { (severe) }\end{array}$ & $<70 \%$ & $<30 \%-50 \%$ \\
\hline $\begin{array}{l}\text { GOLD Stage IV } \\
\text { (very severe) }\end{array}$ & $<70 \%$ & $\begin{array}{l}<30 \% \text { or }<30 \%-50 \% \text { with respiratory } \\
\text { insufficiency (defined as } \mathrm{PaO}_{2}<60 \mathrm{mmHg} \\
\text { and/or } \mathrm{PCO}_{2}<50 \mathrm{mmHg} \text { wile breathing } \\
\text { air at sea level) }\end{array}$ \\
\hline
\end{tabular}

Abbreviations: GOLD, global initiative for chronic obstructive lung disease; COPD, chronic obstructive pulmonary disease; FEVI, forced expiratory volume in I sec; FVC, forced vital capacity; $\mathrm{PaO}_{2}$, partial pressure of oxygen in arterial blood; $\mathrm{PCO}_{2}$, partial pressure of carbon dioxide.

\section{Pathophysiology}

COPD is a complex disease and is often used as an "umbrella" term to incorporate 3 distinct disease processes, chronic bronchitis, emphysema, and small airways disease, which may be present in varying degrees and contribute to the airflow obstruction. ${ }^{1}$ It is worth noting that chronic bronchitis is usually defined by the symptoms of cough and sputum production over the winter months, and this usually may or may not be associated with any indices of airflow obstruction. The increased mucus production due to submucosal gland hypertrophy and hyperplasia in chronic bronchitis coupled with the reduction in mucociliary clearance seen in patients with COPD is a major contributing factor in bacterial colonization and infections, which contributes to exacerbations. ${ }^{19,10}$ The destruction of the parenchyma and enlargement of the alveoli and alveolar ducts distal to the terminal bronchioles termed "emphysema" are likely to contribute to airflow limitation because of a loss of the lung elastic recoil. ${ }^{11}$ The degree of airflow limitation (as measured by FEV1) is correlated with the degree of wall thickening of the small airways, providing evidence of a role for small airway remodeling in the airflow obstruction in COPD. ${ }^{2}$ The decline of lung function and the severity of the disease correlated with the degree of narrowing of the small airways but not with the degree of emphysema or chronic bronchitis present. ${ }^{2}$ This suggests that the narrowing of the small airway may be a predominant factor in the development of airflow limitation in COPD.

The degree of inflammation in the lungs of patients with COPD increases with the severity of the disease. ${ }^{2}$ The inflammation is characterized by an accumulation of neutrophils, macrophages, $\mathrm{B}$ cells, lymphoid aggregates, and $\mathrm{CD} 8^{+} \mathrm{T}$ cells, particularly in the small airways. ${ }^{1,6,12}$ This is likely to represent both innate and adaptive immune responses to the toxic particles and gases. ${ }^{13}$ This inflammation is orchestrated by a complex milieu of proinflammatory mediators, including chemokines, such as CCL2, CXCL1, and CXCL8 (11); cytokines, such as tumor necrosis factor- $\alpha$ (TNF- $\alpha$ ), interleukin (IL)-1 $1 \beta$, IL- 6 , and interferon (IFN)- $\gamma$; and proteases, such as neutrophil elastase and metalloproteinase-9. ${ }^{7}$ As the severity of COPD advances, there is an increase in the numbers of B cells, which may indicate an adaptive immune component to the inflammatory response in the later stages of COPD., ${ }^{2,14}$ Autoimmunity may also play a role in COPD, in particular, caused by cigarette smoke-damaged proteins, with autoantibodies, including antielastin, antiepithelial, and tobacco anti-idiotypic antibodies, detected in smoking patients with COPD. ${ }^{15-17}$ 
Some inflammatory cells also appear to be functionally altered in COPD, which is likely to contribute to the pathogenesis and progression of the disease. In particular, the phagocytic ability of both neutrophils and macrophages is reduced, which is likely to contribute to the ineffective control of bacterial colonization and clearance of dead cells, respectively. ${ }^{18-20}$ Impairment in the clearance of dead and damaged cells is also likely to contribute to the enhancement and chronic nature of the inflammatory response.

\section{Glucocorticoid treatment in COPD}

The abnormal chronic inflammation in the lung of patients with COPD is widely recognized as a prominent driving force in the progression of the disease. However, no current anti-inflammatory treatments significantly modify the chronic inflammatory response or the decline of lung function.

\section{Inhaled glucocorticoids}

Although both inhaled and oral glucocorticoids (GCs) are effective at controlling inflammatory lung diseases such as asthma, their effectiveness is substantially less in COPD; therefore, their contribution to the management of stable COPD is limited. ${ }^{3,21}$ Results published from the TOwards a Revolution in COPD Health (TORCH) study of patients with COPD, with a FEV1 of $<60 \%$, indicated that regular use of inhaled GCs may decrease the rate of decline of lung function. ${ }^{22}$ However, the majority of studies have concluded that the use of regular inhaled GCs has no impact on the long-term progressive decline in FEV1. ${ }^{23-26}$

Regular treatment with inhaled GCs may reduce the frequency of exacerbations of the disease in patients with severe (GOLD stage III) and very severe (GOLD stage IV) COPD. ${ }^{27-29}$ Regular inhaled GCs may also reduce dyspnea and thereby improve health status. ${ }^{30}$ In addition, withdrawal from inhaled GC treatment can lead to increased rates of exacerbations in some patients. ${ }^{31}$ However, treatment with inhaled GCs increases the risk of pneumonia and does not reduce the overall mortality. ${ }^{32-34}$ Therefore, although the majority of studies show that inhaled GCs have no impact on the progression of the decline of lung function, there is evidence that patients with more advanced (GOLD stage III or IV) COPD and repeated exacerbations may derive some benefit. A number of studies have also shown that a combination of long-acting $\beta_{2}$-agonists (LABAs) and inhaled GCs is more effective than either treatment alone in reducing exacerbation frequency, improving lung function, and improving health status..$^{29,30,32,35-38}$ Results from the
TORCH study also indicated that a combination therapy of LABA and inhaled GC may reduce the rate of decline of lung function. ${ }^{22}$ However, similar to the effects of inhaled GC therapy alone, a combination therapy of LABAs and inhaled GCs also increases the likelihood of pneumonia and has no significant effect on overall mortality. ${ }^{32}$

\section{Oral GCs}

An early study suggested that short-term GC effects can predict long-term effects of GCs on FEV1; therefore, short-term use of oral GCs ( 2 weeks) could be recommended to assess if a patient was likely to benefit from long-term use of either inhaled or oral GC therapy. ${ }^{39}$ However, other recent studies indicate that short-term use of oral GCs is a poor predictor of long-term response to inhaled GCs. ${ }^{3,26,40}$ Consequently, GOLD guidelines do not recommend undertaking a therapeutic trial with oral GCs in patients with stage II (moderate), stage III (severe), or stage IV (very severe) COPD who have a poor response to an inhaled bronchodilator. ${ }^{3}$ The short-term response to oral course of prednisolone in terms of increased airway caliber and improved health-related quality of life can be predicted by the presence of sputum eosinophilia. ${ }^{41,42}$

Oral GCs provide benefit in the treatment of COPD exacerbations with a significant reduction in treatment failure and the need for additional medical treatment and shorter hospital stay. ${ }^{43}$ However, the benefits of oral GCs in the treatment of stable COPD are less evident and convincing given the minimal improvements in lung function and the long-term side effects of oral GC therapy ${ }^{44}$ Therefore, although inhaled GCs do have some benefits in the treatment of COPD, particularly in advanced disease, their benefits are limited; both inhaled and oral GC therapies provide more benefit in acute exacerbations: the former prevents the exacerbation and the latter reverses it. However, the modest beneficial effect of inhaled GCs on the frequency of exacerbations has been questioned. ${ }^{45-47}$

\section{GC insensitivity in COPD}

The limited effectiveness of GC treatment in COPD compared with other inflammatory lung conditions such as asthma has led to the concept that the inflammation in the lung of patients with COPD is relatively GC insensitive. ${ }^{21}$ In addition to having no impact on the decline of lung function, inhaled GCs have little effect on the numbers of inflammatory cell or on the release of proinflammatory mediators in the lungs of patients with COPD. ${ }^{48-50}$ This is reflected ex vivo where GCs fail to repress the release of proinflammatory mediators from 
alveolar macrophages obtained from the bronchoalveolar lavage from patients with COPD..$^{51}$

\section{Development of GC insensitivity in COPD \\ Cellular mechanisms}

The molecular mechanisms that contribute to the development of a relative GC-insensitive inflammatory response in COPD remain unclear. First, there is an inherent variation in GC responsiveness between different cell types and tissues. ${ }^{52}$ This may relate to the expression of the dominant negative glucocorticoid receptor (GR) $\beta$ isoform, whose expression correlates with effective GC function in particular cells or tissues. ${ }^{52,53}$ However, the majority of the cells that make up the lung and the infiltrating inflammatory cells in COPD are largely responsive to GCs. In addition, other inflammatory conditions involving many of these cell types are well controlled. It is therefore unlikely that an intrinsic relative GC unresponsiveness of a particular cell type or of the lung itself can fully account for the reduction of GC insensitivity seen in COPD.

One exception to this is neutrophils, where neutrophillic inflammation is relatively unresponsive to GC-mediated immunosuppression compared with other cell type predominant inflammation. ${ }^{45,54,55}$ Neutrophils are not only present in stable COPD but are the predominant infiltrating inflammatory cells in exacerbations of the disease, which are also controlled to a lesser extent by GCs. ${ }^{45}$ Some studies have suggested that this may be due to a relatively high expression of the dominant negative GR $\beta$ isoform. ${ }^{53}$ However, other studies have found low expression of GR $\beta$; therefore, this concept is controversial, and the exact mechanisms behind the reduced effectiveness of GCs on neutrophilic inflammation remains unclear. ${ }^{56}$ It is also unclear whether the GC insensitivity during exacerbations is an extension of the existing GC insensitivity of stable COPD or if there is an additional unresponsiveness mediated by the acute elevation in neutrophils during the exacerbation.

The levels of GR $\beta$ expression have been assessed in COPD, but although the expression of GR $\alpha$ is reduced, there is no apparent change in the expression of GR $\beta .^{55,57}$ It is therefore feasible that a higher level of GR $\beta$ to GR $\alpha$ ratio in the lung or inflammatory cells in patients with COPD may impair GR $\alpha$ function enough to contributing to GC insensitivity. However, with very few studies assessing the relative expressions of GR $\alpha$ and GR $\beta$ in COPD and importantly, any functional impact by an elevation in the ration of GR $\beta$, it is difficult to assign a role for GR $\beta$ in the development of GC insensitivity with any confidence. Impairment of GR $\alpha$ translocation contributes to reduced GC responsiveness in some diseases, such as in a subset of patients with multiple sclerosis where an elevation of expression of heat shock protein 90 (Hsp90) results in increased sequestration of GR $\alpha$ to the cytosol. ${ }^{58}$ However, although there is evidence for an elevation of Hsp90 expression in COPD, and in some assays, oxidant stress can impair GR $\alpha$ translocation in vitro, currently, there is a lack of any compelling in vivo or translational evidence of a role for impaired GR $\alpha$ translocation in COPD GC responsiveness. ${ }^{59,60}$

\section{Genetics}

A number of studies have linked genetic mutations with the development of GC insensitivity. ${ }^{52}$ In patients with asthma, 11 genes have now been identified, which may discriminate between relative $\mathrm{GC}$-insensitive and $\mathrm{GC}$ - sensitive patients with asthma, suggesting that there may be a genetic factor in the development of relatively GC-insensitive asthma. ${ }^{61}$ A direct link between genetic mutations and the development of relative GC insensitivity in COPD has not been established. However, there is evidence that genetic susceptibility is likely to play a role in the development of COPD. Studies investigating the antioxidant capacity of the lungs of patients with COPD and smokers suggest that subjects that develop COPD have a reduced capacity to elevate their antioxidant defenses, which may, in part, account for the development of COPD in a subset of smokers $(-20 \%)$ rather than all smokers. ${ }^{62-64}$ Interestingly, the 213 Gly variant of the antioxidant extracellular superoxide dismutase 3 (SOD3), which affects approximately $2 \%$ of the population, increases the plasma SOD3 levels 10-fold and has been associated with a protection in smokers to the consequent development of COPD. ${ }^{63,65}$ Furthermore, given the likely central role for oxidant stress in the development of GC insensitivity (discussed in the following section), the reduced antioxidant capacity is also likely to contribute to the development of a relative GC insensitivity in COPD.

\section{Oxidative stress}

As the innate or helper $\mathrm{T}$ cell type $1\left(\mathrm{~T}_{\mathrm{H}} 1\right)$ inflammatory response is well documented as responding well to GCs, the enhanced and relatively GC-insensitive inflammatory cell present in the lungs of patients with COPD is likely to incorporate an underlying factor. One prominent theory is that an elevation in the oxidant burden in the lungs (termed "oxidative stress") plays a central role in both the enhancement of the inflammatory response and the development of 
a relative GC insensitivity. ${ }^{1,66}$ This concept is supported by experimental and mechanistic evidence and is also in alignment with other proposed mechanisms including direct disruption of GR $\alpha$ corepressor activity and alteration of kinase signaling, discussed below.

The elevation in the oxidant burden in the lungs of patients with COPD may be derived both from exogenous sources, such as pollution and cigarette smoke, and endogenous sources, such as respiratory burst of proinflammatory cells, such as macrophages and neutrophils. Physiologically, oxidants and the redox state of the cell are an integral part of cellular signaling and function including that of GR $\alpha{ }^{67,68}$ However, a significant elevation in the oxidants can overcome both intracellular and extracellular antioxidant defenses leading to significant alterations in signaling pathways and protein function. ${ }^{69}$ The role of exogenous oxidative stress derived from cigarette smoke is highlighted by its induction of reduced GC insensitivity in experimental models and the development of relative GC insensitivity in mild or moderate asthma patients who smoke. ${ }^{1,55,70,71}$

\section{Oxidant stress: HDAC and corepressor function}

A central factor in both an oxidant-mediated enhancement of inflammatory responses and development of relative GC insensitivity may be facilitated by a direct alteration in the acetylation-deacetylation balance of the core histone proteins. ${ }^{72,73}$ A central part of GR $\alpha$ function is the recruitment of corepressor complexes containing histone deacetylases (HDACs), which remove acetyl groups from the NH-terminal tails of core histone proteins. ${ }^{73-75}$ These acetyl groups on the histone tails confer a "relaxed" transcriptionally open structure to the promoter region of the genes, and their removal results in reassociation of the DNA around the core histones and gene silencing. ${ }^{73,74,76}$ In vitro studies using small interfering RNA and overexpression models have shown that HDAC-2 is the key in the functional mechanism of GC-mediated or GR $\alpha$-mediated histone deacetylation and gene repression. ${ }^{77}$

Acutely, oxidative stress reduces HDAC-2 activity with a reduction in HDAC-2 protein expression seen with more chronic oxidant exposures in in vitro and in vivo models. ${ }^{71,78,79}$ This reduction in HDAC-2 activity and expression is strongly associated with oxidant-mediated covalent modifications, including hyperphosphorylation, nitration, and carbonylation, which impair protein activity and enhance proteasomal degradation. ${ }^{72,73,78-83}$ These modifications are mediated by reactive oxygen, including reactive carbonyls and reactive nitrogen species, and by kinase signaling pathways activated by oxidant stress. ${ }^{72,73,83}$ Although the exact mechanisms and pathways that regulate these modifications remain unclear, recent work has suggested that oxidants modulate HDAC-2 phosphorylation and subsequent ubiquitination followed by proteasomal degradation through a protein kinase CK2 $\alpha$-dependant mechanism..$^{84,85}$

The acetylation - deacetylation balance of histone is a highly regulated process and central in the control of gene transcription. ${ }^{74}$ Therefore, this oxidant-mediated loss of HDAC-2 activity and resulting imbalance in histone acetylation status are likely to contribute to the enhanced inflammatory responses in this disease. In agreement with this, HDAC-2 activity and expression are reduced in the peripheral lungs of patients with COPD, which correlate with disease severity. ${ }^{86}$ Furthermore, as HDAC-2 activity is fundamental for functional GR $\alpha$ transrepression of proinflammatory genes, a reduction in its activity and expression is lightly to impair GC function and thereby contributes to a reduction in GC responsiveness (Figure 1). Similarly, in models where HDAC-2 activity is compromised, GC function is reduced, and restoration or protection of HDAC-2 activity is correlated with a restoration in GC sensitivity. ${ }^{55,87}$ Therefore, there is strong evidence that the reduction in HDAC-2 activity and expression seen in patients with COPD is likely to be an important factor in the mechanisms of the relative GC insensitivity in this disease. In addition, as there is a reduction in expression of other HDACs in COPD, including HDAC-3, 5 , and 8 , it must also be considered that the alteration in the expression and/or activity of other HDACs may also play a role in the impairment of GC function. ${ }^{86}$ Cigarette smoke exposure results in a reduction of HDAC-1, 2, and 3 in the macrophage cell line, Mono Mac 6 cells, associated with elevated tyrosine nitration and aldehyde adduct formation. ${ }^{88}$ However, the roles of these HDACs in the lung and inflammatory cells involved in COPD are poorly understood, and studies are needed to clarify their roles in GR function and in disease.

\section{Kinase signaling}

Kinase signaling is integral to the orchestration of the inflammatory response. ${ }^{89}$ However, some of these kinase pathways are elevated in COPD and may also play a role in the development of GC insensitivity in the disease. The expression of p38 mitogen-activated protein kinase (MAPK) is elevated in the peripheral lungs and alveolar macrophages in patients with mild or moderate COPD compared with smokers. ${ }^{90}$ This study also suggested 


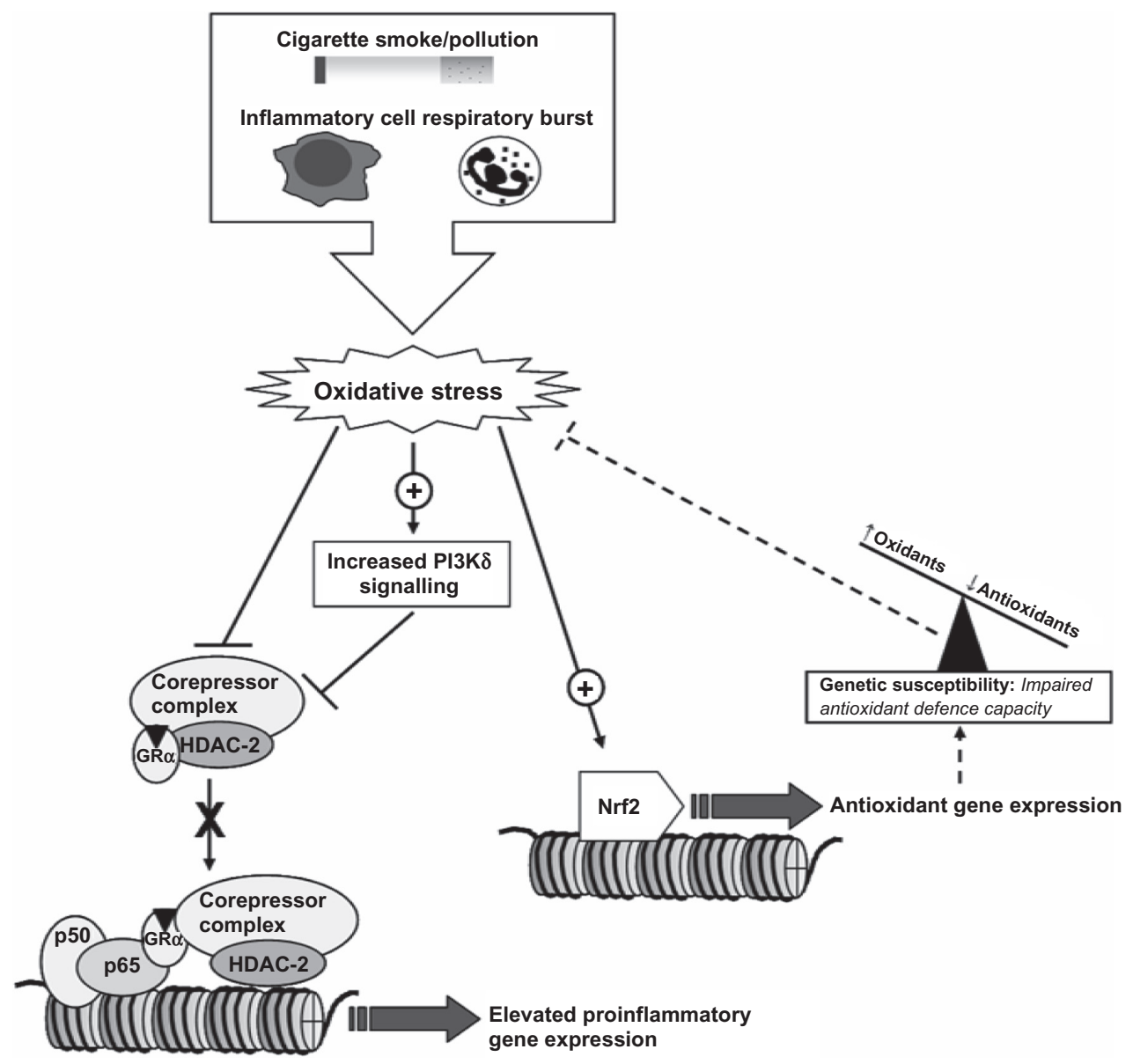

Figure I Simplified diagrammatic representation of the mechanisms involved in an oxidant-mediated relative reduction of GC sensitivity. Oxidative stress generated by both

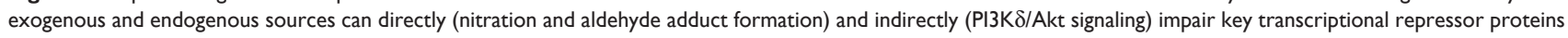
utilizing the GR $\alpha$ including HDAC-2, thus preventing GC-mediated repression of proinflammatory mediators. If the antioxidant defense response is impaired, this oxidant imbalance results in elevated inflammatory mediator expression, which GC is unable to repress.

Abbreviations: GC, glucocorticoid; PI3K, phosphoinositide 3-kinase; GR, glucocorticoid receptor; HDAC, histone deacetylase; Nrf2, NF-E2-related factor 2 (a major regulator of antioxidant gene expression).

an inverse correlation between the activation of $\mathrm{p} 38$ MAPK and the reduction in FEV1 and FEV1/FVC..$^{90}$ An elevation of p38 MAPK may be responsible for an increase in phosphorylation of GR $\alpha$ in a manner that results in a reduction of its ligand-binding ability. ${ }^{91}$ A negative feedback mechanisms used by GCs to regulate the inhibitory effect of p38 MAPK on GR $\alpha$ in an induction of MAPK phosphatase-1 (MKP-1) expression, which reduced p38 MAPK activity by dephosphorylation (REF). A study looking at patients with severe asthma vs nonsevere asthma found a reduction in the dexamethasone-induced expression (messenger RNA) of MKP-1 and elevation in p38 activity in patients with severe asthma compared with patients with nonsevere asthma. ${ }^{92}$ However, no studies have looked at the GC-mediated induction of MKP-1 in COPD, and consequently no links have yet been made between the expression, activity, or signaling of MKP-1 and the reduction in GC responsiveness in COPD, although the potential is clearly explained.
There is also increasing evidence that a plethora of other kinases and signaling pathways, including glycogen synthase kinase- $3 \beta$, extracellular signal-regulated kinase-1/2, and c-Jun N-terminal kinase, can directly regulate the activity of GR $\alpha$ through phosphorylation and thereafter may also influence its gene specificity. ${ }^{93,94}$

Oxidant stress also activates various kinase pathways, including the phosphoinositide 3-kinase (PI3K)/Akt pathway through selective activation of the PI $3 \mathrm{~K} \delta$ isoform (Figure 1). ${ }^{95,96}$ Our recent study has shown that the activation of both PI3K $\delta$ and Akt is elevated in macrophages from the peripheral lungs of patients with COPD. ${ }^{96}$ Specific inhibition of PI3K $\delta / A k t$ signaling pathway restores and protects both HDAC-2 activity and GC function in oxidant-mediated GC-insensitive models. ${ }^{55}$ Similarly, selective inhibition of $\mathrm{PI} 3 \mathrm{~K} \delta /$ Akt pathway restores the ability of GCs to repress inflammatory mediator expression in patients with COPD comparable to smokers with normal lung function. ${ }^{96}$ 
However, although the mechanism by which inhibition on $\mathrm{PI} 3 \mathrm{~K} \delta$ protects GC function appears to be mediated through the protection of HDAC-2 activity, it is also likely to include modulation of other corepressors, such as Mi-2 and $\mathrm{mSin} 3 \mathrm{a}^{55,97}$ The mechanism by which PI3K $\delta$ affects HDAC-2 activity and GR $\alpha$ function appears to involve oxidant-mediated covalent modifications, including tyrosine nitration and hyperphosphorylation induced by the oxidative stress. ${ }^{55}$ However, the mechanisms and pathways that elicited downstream of $\mathrm{PI} 3 \mathrm{~K} \delta / \mathrm{Akt}$ signaling during oxidant stress, which facilitates the modification of HDAC-2 and expression of other corepressors, remain unclear.

\section{Strategies for overcoming GC insensitivity in COPD Restoration of GC function}

GCs provide an effective treatment for the control of both acute and chronic inflammation in many diseases. Their delivery, side effects, and drug-drug interactions are all well characterized; therefore, the ability to restore the function of GC in COPD is a favorable strategy. The methylxanthine theophylline has been shown to provide a GC "sparing" effect when given at a low concentration with GCs. ${ }^{98} \mathrm{~A}$ low dose of theophylline may also improve the anti-inflammatory action of $\mathrm{GC}$ in an exacerbation of COPD. ${ }^{99}$ However, the exact mechanism of this GC "sparing” action is unclear. Theophylline is often described as a phosphodiesterase (PDE) inhibitor but is also known to have many "off-target" interactions including gene regulation. ${ }^{100}$ Importantly, the concentrations that can achieve this GC sparing are below the concentration at which it targets PDE. This is further complicated by an interesting observation that the binding profile of theophylline is significantly different in cells that have been exposed to oxidative stress and is therefore likely to be different in patients with COPD and those with their higher oxidant burden in lung. ${ }^{100,101}$ Although the exact direct molecular targets of theophylline that confer this GC sparing or enhancing activity remain unresolved, the downstream mechanism involves the restoration of HDAC activity. ${ }^{87,102,103}$

In addition to theophylline, the curcumin, a polyphenolic natural compound, has also demonstrated an ability to restore GC function in vitro. ${ }^{104,105}$ Similar to theophylline, the curucmin-mediated restoration of GC function is proposed to work through a protection of HDAC-2 expression and activity. ${ }^{79}$ However, as with theophylline, curcumin has a seemingly wide and relatively nonspecific action at a range of concentrations including activation and repression of several kinases and transcription factors. Although functionally it has been documented as antioxidant, anti-inflammatory, and GC protective, the precise molecular targets for these specific actions may be difficult to elucidate, and further studies into the precise molecular effectors of its actions are required. ${ }^{106}$

Selective inhibition of $\mathrm{PI} 3 \mathrm{~K} \delta$ also restores the ability of GCs to repress inflammatory mediator expression, which appears to be through protection and/or restoration of HDAC-2 activity. ${ }^{55}$ This similarity between the reported mechanisms may indicate that theophylline may be mediated its action through inhibition of the PI $3 K \delta$ pathway, but although theophylline does inhibit various PI3K isoforms at high concentrations, a direct link at a low concentration in oxidant-stressed cells has yet to be made. ${ }^{100}$ The PI3K $\delta$ and $\gamma$ isoforms are also relatively leukocyte specific and are central in the orchestration of both the innate and the adaptive immune responses, including neutrophil recruitment, high-affinity IgE receptor (FceRI) signaling, and chemokine signaling. ${ }^{107-112}$ Selective $\mathrm{PI} 3 \mathrm{~K} \delta / \gamma$ inhibitors have received intense interest from the pharmaceutical industry and are being developed as anti-inflammatory drugs, particularly for allergic disease. Therefore, with selective PI3K isoform inhibitors currently under development, the targeting of $\mathrm{PI} 3 \mathrm{~K} \delta$ may be preferable to theophylline whose mechanism remains unclear and has no additional anti-inflammatory effect itself (Figure 2).

\section{Alternative anti-inflammatory agents}

Alternative anti-inflammatory targets have been proposed for COPD. TNF- $\alpha$ is a central mediator in the inflammatory response seen in the lungs of patients with COPD. ${ }^{7}$ However, a trial with the anti-TNF- $\alpha$ antibody infliximab determined that there was no benefit in moderate to severe COPD, and this was associated with severe adverse events, particularly cancer and lung infections. ${ }^{113}$ Selective p38 MAPK $\alpha$ inhibitors are potent at suppressing the release of proinflammatory mediators in vitro including those closely associated with COPD, such as TNF- $\alpha$ and CXCL8. ${ }^{114,115}$ Selective inhibition of p38 MAPK $\alpha$ also suppresses oxidant-mediated lung inflammation in mice where GCs are not effective, indicating that the functional anti-inflammatory properties of p38 MAPK inhibitors are not adversely affected by oxidant stress. ${ }^{116,117}$ The expression of p38 MAPK is elevated in the lungs of patients with COPD, and the selective inhibitors reduce the expression of inflammatory markers in the blood of patients with COPD. ${ }^{118}$ This suggests that selective targeting of $\mathrm{p} 38$ MAPK in COPD may provide a potentially effective alternative therapeutic strategy to GCs 


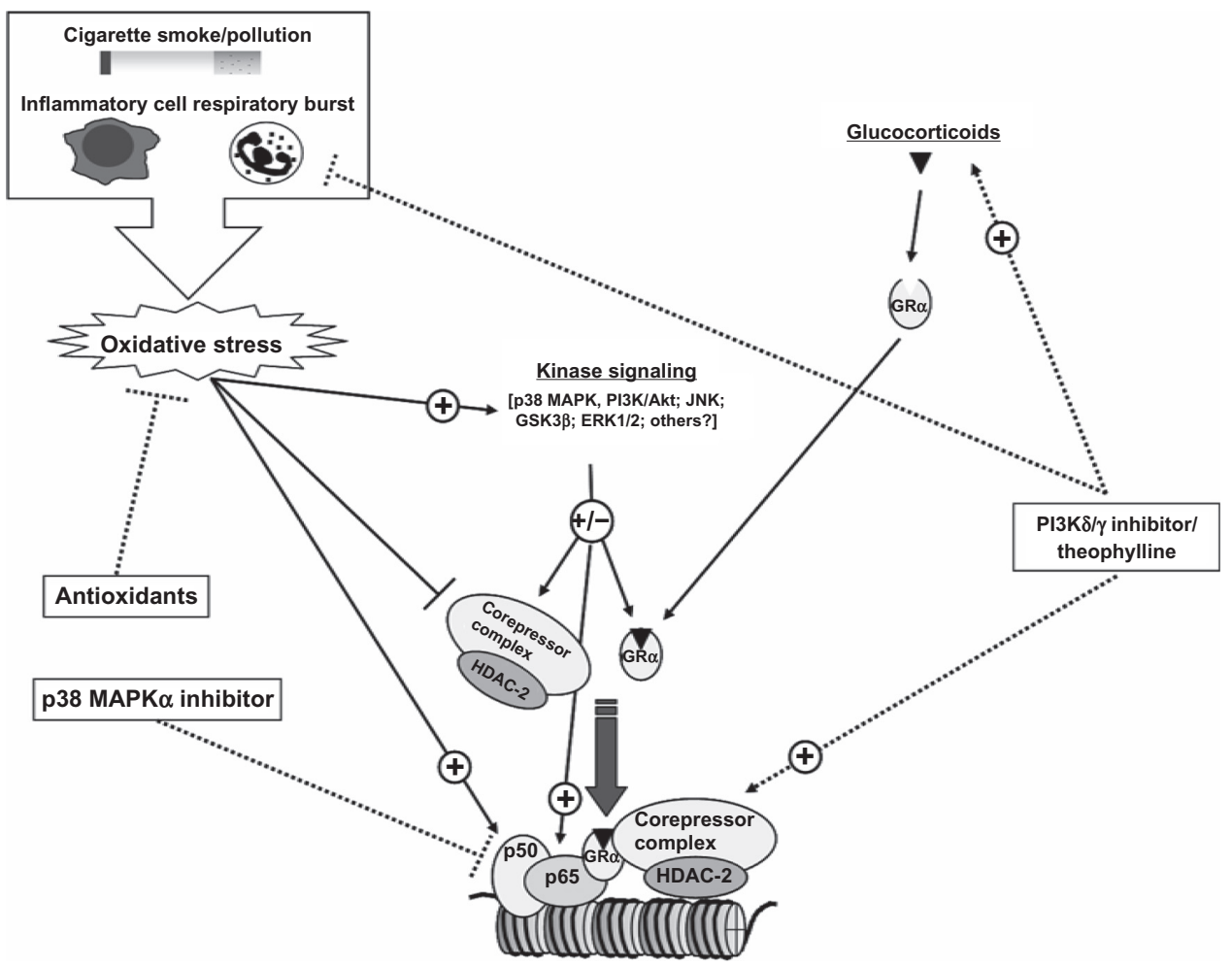

Figure 2 Possible therapeutic strategies for alternative effective anti-inflammatory drugs or for the additional restoration of GC function for an oxidant-mediated reduction in GC sensitivity. An effective antioxidant would combat one of the major contributing factors to the chronic and relatively GC unresponsive inflammation in COPD. Current therapies such as theophylline may be able to restore the effectiveness of GCs, thus allowing GC to be more effective in COPD. Oxidant-driven alterations in kinase signaling are likely to contribute to the impaired GR $\alpha$ function in COPD and selective targeting of these pathways, such as PI3K $\delta$ and p38 MAPK, which could also restore the effectives of GC in COPD. In addition, alternative anti-inflammatory inhibitors, such as PI3K $\delta / \gamma$ or p38 MAPK, may also provide effective alternative or combinatorial anti-inflammatory strategy to GCs in the oxidant-driven inflammation in COPD.

Abbreviations: GC, glucocorticoid; COPD, chronic obstructive pulmonary disease; GR, glucocorticoid receptor; PI3K, phosphoinositide 3-kinase; MAPK, mitogen-activated protein kinase; JNK, c-Jun N-terminal kinase; GSK, glycogen synthase kinase; ERK, extracellular signal-regulated kinase; HDAC, histone deacetylase.

(Figure 2), particularly that it may also enhance the effect of any concomitant GC therapy. However, p38 MAPK $\alpha$ is important in many cell functions, and one major hurdle facing the development of selective p38 MAPK $\alpha$ inhibitors appears to be cytotoxicity. ${ }^{119}$

\section{Proresolving strategies}

A significant driving force behind an enhanced and persistent inflammation may be an inability of the inflammation to resolve and thereby self-regulate. This is likely to be an integral factor in COPD where even after the removal of the exogenous driving force (predominantly, cigarette smoke), the inflammatory response continues. This impairment of inflammatory resolution may be particularly important in the context of GC treatment in COPD.

Although GCs are not effective at repressing neutrophilic inflammation, studies have shown that GCs can significantly impair the rate of constitutive apoptosis of neutrophils. ${ }^{120}$ This constitutive cell death is an important "safety" feature of neutrophil function, which prevents a prolonged release of toxic and damaging agents, such as superoxide and neutrophil elastase, which may damage otherwise healthy tissue, thereby perpetuating the inflammatory response. ${ }^{121}$ Controlled cell death termed "apoptosis" is a key feature of neutrophil cell death, as this prevents the release of the toxic and inflammatory contents of the dead cell and also targets the cell for phagocytosis and clearance by macrophages. ${ }^{121-123}$ The nonphlogistic clearance of apoptotic neutrophils is also considered a central feature in inflammatory resolution, as it triggers a switch in the phenotype of the macrophages from proinflammatory to proresolving with the release of proresolving mediators, such as prostaglandin $\mathrm{E}_{2}$ and IL-10. ${ }^{121,124-126}$

Macrophage phagocytosis is impaired in COPD, which may be due to the effect of cigarette smoke, and therefore, the rate of the clearance of apoptotic neutrophils is likely to be reduced. ${ }^{127,128}$ If GC treatment of patients with COPD reflects what is seen in in vitro assays with a delay in neutrophil apoptosis, then the neutrophil may not only be living longer and releasing more inflammatory 
agents but also be fueling the destruction of the lung and inflammatory response by the release of its cellular contents through necrosis due to its defective clearance by resident macrophages. A few studies have looked into inflammatory resolution in COPD, and there is little direct information on the impact of GCs; however, this area may prove to be useful in finding potentially effective and novel anti-inflammatory drugs for COPD.

Interestingly, in addition to their role in initiation of both innate and adaptive immune responses and a potential role in the restoration of GC function, PI3Ks may also play an important role in the resolution of inflammation. The resolution or allergen-induced eosinophilic inflammation is enhanced by inhibition of PI3K by a mechanism involving blockade of Akt activation and enhanced cell apoptosis. ${ }^{129}$ Studies using both transgenic mice and selective inhibitors have demonstrated that $\mathrm{PI} 3 \mathrm{~K} \beta$ is required for functional $\mathrm{Fc} \gamma$ receptor-mediated macrophage phagocytosis. ${ }^{130}$ Therefore, in addition to their anti-inflammatory action, selective PI3K inhibitors may also promote inflammatory resolution and thereby may provide an additional therapeutic benefit. A range of other small-molecule inhibitors that target the rate of neutrophil apoptosis has also been developed. These include inhibitors of cyclin-dependant kinases such as roscovitine, which have recently been shown to promote neutophil apoptosis and inflammatory resolution in vivo. ${ }^{123}$ Therefore, selective inhibitors that promote neutrophil cell death may also provide a therapeutic inflammatory proresolution strategy, although the effectiveness of this in the presence of defective clearance must be investigated. Another approach to promoting the resolution of inflammation is the therapeutic use of molecules that mimic the actions of potent endogenous proresolving mediators such as the lipid mediator resolvin E1. ${ }^{131}$ Such therapies are currently under development, including the resolvin E1 mimetic (Resolvyx ${ }^{\mathrm{TM}}$ ); however, their potential therapeutic application in COPD has yet to be investigated.

\section{Summary}

GCs are not effective at controlling the chronic inflammatory response in COPD. This persistent and abnormal inflammation in the lung increases as the disease progresses. To date, there are no effective treatments to control this persistent inflammatory response and the associated decline of lung function of COPD. This is largely due to a lack of understanding the nature of the inflammatory response in COPD and the impact of key underlying factors such as oxidative stress on this inflammatory response.
It is clear that an effective anti-inflammatory therapy is likely to play a central role in the effective management of the disease in the future. It is therefore critical that we understand the mechanism of the abnormal inflammatory response in COPD, including the defective ability of GC-activated GR $\alpha$ to repress proinflammatory responses. Therapeutic targeting is likely to involve the oxidant-mediated alterations in kinase signaling and protein function, such as p 38 MAPK, PI3K $\delta$, and GR $\alpha$ corepressors including HDAC-2. A more detailed elucidation of these pathways is needed before selected targets can be identified. In addition, agents that can restore GC sensitivity could be developed through an understanding of oxidant stress effects on GRs and signaling pathways. Some of these agents may also confer effective anti-inflammatory effects in COPD themselves. Finally, given the lack of successful anti-inflammatory drugs for COPD, a combination therapy directed in tandem against other aspects of the inflammatory response such as antioxidants and proresolving therapies may prove to be more effective at controlling the inflammation and thereafter halting the decline of both lung function and disease progression.

\section{Acknowledgments}

This study was supported by the UK Medical Research Council and Medical Research Scotland (Marwick) and by the UK Medical Research Council and the Wellcome Trust grants (Chung).

\section{Disclosure}

The authors report no conflicts of interest in this work.

\section{References}

1. Chung KF, Adcock IM. Multifaceted mechanisms in COPD: inflammation, immunity, and tissue repair and destruction. Eur Respir J. 2008;31(6):1334-1356.

2. Hogg JC, Chu F, Utokaparch S, et al. The nature of small-airway obstruction in chronic obstructive pulmonary disease. $N$ Engl $\mathrm{J} \mathrm{Med}$. 2004;350(26):2645-2653.

3. Rabe KF, Hurd S, Anzueto A, et al. Global strategy for the diagnosis, management, and prevention of chronic obstructive pulmonary disease: GOLD executive summary. Am J Respir Crit Care Med. 2007;176(6):532-555.

4. Mannino DM, Buist AS. Global burden of COPD: risk factors, prevalence, and future trends. Lancet. 2007;370(9589):765-773.

5. Buist AS, McBurnie MA, Vollmer WM, et al. International variation in the prevalence of COPD (the BOLD Study): a population-based prevalence study. Lancet. 2007;370(9589):741-750.

6. Barnes PJ. Immunology of asthma and chronic obstructive pulmonary disease. Nat Rev Immunol. 2008;8(3):183-192.

7. Barnes PJ. The cytokine network in asthma and chronic obstructive pulmonary disease. J Clin Invest. 2008;118(11):3546-3556.

8. World Health Organisation. WHO Statistical Information System (WHOSIS). Available from: http://www.who.int/whosis/whostat/2008/ en/index.html. Published 2008 Jan 1. 
9. Patel IS, Seemungal TAR, Wilks M, Lloyd-Owen SJ, Donaldson GC, Wedzicha JA. Relationship between bacterial colonisation and the frequency, character, and severity of COPD exacerbations. Thorax. 2002;57(9):759-764.

10. Sethi S. Bacterial infection and the pathogenesis of COPD. Chest. 2000;117(5 Suppl 1):286S-291S.

11. Kim WD, Eidelman DH, Izquierdo JL, Ghezzo H, Saetta MP, Cosio MG. Centrilobular and panlobular emphysema in smokers. Two distinct morphologic and functional entities. Am Rev Respir Dis. 1991;144(6): $1385-1390$.

12. Hogg JC. Pathophysiology of airflow limitation in chronic obstructive pulmonary disease. Lancet. 2004;364(9435):709-721.

13. Cosio MG, Saetta M, Agusti A. Immunologic aspects of chronic obstructive pulmonary disease. $N$ Engl J Med. 2009;360(23): 2445-2454.

14. Gosman MME, Willemse BWM, Jansen DF, et al. Increased number of B-cells in bronchial biopsies in COPD. Eur Respir J. 2006;27(1):60-64.

15. Lee SH, Goswami S, Grudo A, et al. Antielastin autoimmunity in tobacco smoking-induced emphysema. Nat Med. 2007;13(5):567-569.

16. Feghali-Bostwick CA, Gadgil AS, Otterbein LE, et al. Autoantibodies in patients with chronic obstructive pulmonary disease. Am J Respir Crit Care Med. 2008;177(2):156-163.

17. Koethe SM, Kuhnmuench JR, Becker CG. Neutrophil priming by cigarette smoke condensate and a tobacco anti-idiotypic antibody. $\mathrm{Am}$ J Pathol. 2000;157(5):1735-1743.

18. Stringer KA, Tobias M, O’Neill HC, Franklin CC. Cigarette smoke extract-induced suppression of caspase-3-like activity impairs human neutrophil phagocytosis. Am J Physiol Lung Cell Mol Physiol. 2007;292(6):L1572-L1579.

19. Berenson C, Garlipp M, Grove L, Maloney J, Sethi S. Impaired phagocytosis of nontypeable Haemophilus influenzae by human alveolar macrophages in chronic obstructive pulmonary disease. J Infect Dis. 2006;194(10):1375-1384.

20. Taylor AE, Finney-Hayward TK, Quint JK, et al. Defective macrophage phagocytosis of bacteria in COPD. Eur Respir J. 2010;35(5): 1039-1047.

21. Barnes PJ, Adcock IM. Glucocorticoid resistance in inflammatory diseases. Lancet. 2009;373(9678):1905-1917.

22. Celli BR, Thomas NE, Anderson JA, et al. Effect of pharmacotherapy on rate of decline of lung function in chronic obstructive pulmonary disease: results from the TORCH study. Am J Respir Crit Care Med. 2008;178(4):332-338.

23. Vestbo Jo, Sorensen T, Lange P, Brix A, Torre P, Viskum K. Longterm effect of inhaled budesonide in mild and moderate chronic obstructive pulmonary disease: a randomised controlled trial. Lancet. 1999;353(9167):1819-1823.

24. Pauwels RA, Lofdahl CG, Laitinen LA, et al. Long-term treatment with inhaled budesonide in persons with mild chronic obstructive pulmonary disease who continue smoking. $N$ Engl $J$ Med. 1999;340(25):1948-1953.

25. The Lung Health Study Research Group. Effect of inhaled triamcinolone on the decline in pulmonary function in chronic obstructive pulmonary disease. N Engl J Med. 2000;343(26):1902-1909.

26. Burge PS, Calverley PM, Jones PW, Spencer S, Anderson JA, Maslen TK. Randomised, double blind, placebo controlled study of fluticasone propionate in patients with moderate to severe chronic obstructive pulmonary disease: the ISOLDE trial. BMJ. 2000; 320(7245):1297-1303.

27. Spencer S, Calverley PM, Burge PS, Jones PW. Impact of preventing exacerbations on deterioration of health status in COPD. Eur Respir J. 2004;23(5):698-702.

28. Jones PW, Willits LR, Burge PS, Calverley PM. Disease severity and the effect of fluticasone propionate on chronic obstructive pulmonary disease exacerbations. Eur Respir J. 2003;21(1):68-73.
29. Calverley P, Pauwels R, Vestbo J, et al. Combined salmeterol and fluticasone in the treatment of chronic obstructive pulmonary disease: a randomised controlled trial. Lancet. 2003;361(9356):449-456.

30. Mahler DA, Wire P, Horstman D, et al. Effectiveness of fluticasone propionate and salmeterol combination delivered via the Diskus device in the treatment of chronic obstructive pulmonary disease. Am J Respir Crit Care Med. 2002;166(8):1084-1091.

31. van der Valk P, Monninkhof E, van der Palen J, Zielhuis G, van Herwaarden C. Effect of discontinuation of inhaled corticosteroids in patients with chronic obstructive pulmonary disease: the COPE study. Am J Respir Crit Care Med. 2002;166(10):1358-1363.

32. Calverley PM, Anderson JA, Celli B, et al. Salmeterol and fluticasone propionate and survival in chronic obstructive pulmonary disease. N Engl J Med. 2007;356(8):775-789.

33. Drummond MB, Dasenbrook EC, Pitz MW, Murphy DJ, Fan E. Inhaled corticosteroids in patients with stable chronic obstructive pulmonary disease: a systematic review and meta-analysis. JAMA. 2008;300(20):2407-2416.

34. Singh S, Amin AV, Loke YK. Long-term use of inhaled corticosteroids and the risk of pneumonia in chronic obstructive pulmonary disease: a meta-analysis. Arch Intern Med. 2009;169(3):219-229.

35. Szafranski W, Cukier A, Ramirez A, et al. Efficacy and safety of budesonide/formoterol in the management of chronic obstructive pulmonary disease. Eur Respir J. 2003;21(1):74-81.

36. Hanania NA, Darken P, Horstman D, et al. The efficacy and safety of fluticasone propionate $(250 \mathrm{microg}) / \mathrm{salmeterol}(50 \mathrm{microg})$ combined in the Diskus inhaler for the treatment of COPD. Chest. 2003;124(3):834-843.

37. Calverley PM, Boonsawat W, Cseke Z, Zhong N, Peterson S, Olsson H. Maintenance therapy with budesonide and formoterol in chronic obstructive pulmonary disease. Eur Respir J. 2003;22(6): 912-919.

38. Kardos P, Wencker M, Glaab T, Vogelmeier C. Impact of salmeterol/ fluticasone propionate versus salmeterol on exacerbations in severe chronic obstructive pulmonary disease. Am J Respir Crit Care Med. 2007;175(2):144-149.

39. Callahan CM, Dittus RS, Katz B. Oral corticosteroid therapy for patients with stable chronic obstructive pulmonary disease. A meta-analysis. Ann Intern Med. 1991;114(3):216-223.

40. Burge PS, Calverley PM, Jones PW, Spencer S, Anderson JA. Prednisolone response in patients with chronic obstructive pulmonary disease: results from the ISOLDE study. Thorax. 2003;58(8):654-658.

41. Brightling CE, McKenna S, Hargadon B, et al. Sputum eosinophilia and the short term response to inhaled mometasone in chronic obstructive pulmonary disease. Thorax. 2005;60(3):193-198.

42. Pizzichini E, Pizzichini M, Gibson P, et al. Sputum eosinophilia predicts benefit from prednisone in smokers with chronic obstructive bronchitis. Am J Respir Crit Care Med. 1998;158(5):1511-1517.

43. Walters J, Gibson P, Wood-Baker R, Hannay M, Walters E. Systemic corticosteroids for acute exacerbations of chronic obstructive pulmonary disease. Cochrane Database Syst Rev. 2009;1:CD001288.

44. Wood-Baker R, Walters J, Haydn Walters E. Systemic corticosteroids in chronic obstructive pulmonary disease: an overview of Cochrane systematic reviews. Respir Med. 2007;101(3):371-377.

45. Barnes PJ. New molecular targets for the treatment of neutrophilic diseases. J Allergy Clin Immunol. 2007;119(5):1055-1062.

46. Yang I, Fong K, Sim E, Black PN, Lasserson TJ. Inhaled corticosteroids for stable chronic obstructive disease. Cochrane Database Syst Rev. 2007;2:CD002991.

47. Suissa S, Ernst P, Vandemheen KL, Aaron SD. Methodological issues in therapeutic trials of COPD. Eur Respir J. 2008;31(5):927-933.

48. Culpitt SV, Maziak W, Loukidis S, Nightingale JA, Matthews JL, Barnes PJ. Effect of high dose inhaled steroid on cells, cytokines, and proteases in induced sputum in chronic obstructive pulmonary disease. Am J Respir Crit Care Med, 1999;160(5):1635-1639. 
49. Keatings VM, Jatakanon A, Worsdell YM, Barnes PJ. Effects of inhaled and oral glucocorticoids on inflammatory indices in asthma and COPD. Am J Respir Crit Care Med. 1997;155(2):542-548.

50. Bourbeau J, Christodoulopoulos P, Maltais F, Yamauchi Y, Olivenstein R, Hamid Q. Effect of salmeterol/fluticasone propionate on airway inflammation in COPD: a randomised controlled trial. Thorax. 2007;62(11):938-943.

51. Culpitt SV, Rogers DF, Shah P, et al. Impaired inhibition by dexamethasone of cytokine release by alveolar macrophages from patients with chronic obstructive pulmonary disease. Am J Respir Crit Care Med. 2003;167(1):24-31.

52. Gross KL, Cidlowski JA. Tissue-specific glucocorticoid action: a family affair. Trends Endocrinol Metab. 2008;19(9):331-339.

53. Strickland I, Kisich K, Hauk PJ, et al. High constitutive glucocorticoid receptor beta in human neutrophils enables them to reduce their spontaneous rate of cell death in response to corticosteroids. J Exp Med. 2001;193(5):585-594.

54. Ito K, Herbert C, Siegle JS, et al. Steroid-resistant neutrophilic inflammation in a mouse model of an acute exacerbation of asthma. Am J Respir Cell Mol Biol. 2008;39(5):543-50.

55. Marwick JA, Caramori G, Stevenson CS, et al. Inhibition of PI3Kdelta restores glucocorticoid function in smoking-induced airway inflammation in mice. Am J Respir Crit Care Med. 2009;179(7): 542-548.

56. Pujols L, Mullol J, Roca-Ferrer J, et al. Expression of glucocorticoid receptor alpha- and beta-isoforms in human cells and tissues. Am J Physiol Cell Physiol. 2002;283(4):C1324-C1331.

57. Korn SH, Thunnissen FBJM, Wesseling GJ, Arends J-W, Wouters EFM. Glucocorticoid receptor mRNA levels in bronchial epithelial cells of patients with COPD: influence of glucocorticoids. Respir Med. 1998;92(9):1102-1109.

58. Matysiak M, Makosa B, Walczak A, Selmaj K. Patients with multiple sclerosis resisted to glucocorticoid therapy: abnormal expression of heat-shock protein 90 in glucocorticoid receptor complex. Mult Scler. 2008;14(7):919-926.

59. Hacker S, Lambers C, Heotzenecker K, et al. Elevated HSP27, HSP70 and HSP90 alpha in chronic obstructive pulmonary disease: markers for immune activation and tissue destruction. Clin Lab. 2009;55(1-2):31-40.

60. Okamoto K, Tanaka H, Ogawa $\mathrm{H}$, et al. Redox-dependent regulation of nuclear import of the glucocorticoid receptor. J Biol Chem. 1999;274(15):10363-10371.

61. Hakonarson H, Bjornsdottir US, Halapi E, et al. Profiling of genes expressed in peripheral blood mononuclear cells predicts glucocorticoid sensitivity in asthma patients. Proc Nat Acad Sci U S A. 2005;102(41):14789-14794.

62. Smolonska J, Wijmenga C, Postma DS, Boezen HM. Meta-analyses on suspected chronic obstructive pulmonary disease genes: a summary of 20 Years' Research. Am J Respir Crit Care Med. 2009;180(7): 618-631.

63. Young RP, Hopkins R, Black PN, et al. Functional variants of antioxidant genes in smokers with COPD and in those with normal lung function. Thorax. 2006;61(5):394-399.

64. Mak JC, Ho SP, Yu WC, et al. Polymorphisms and functional activity in superoxide dismutase and catalase genes in smokers with COPD. Eur Respir J. 2007;30(4):684-690.

65. Juul K, Tybjaerg-Hansen A, Marklund S, Lange P, Nordestgaard BG. Genetically increased antioxidative protection and decreased chronic obstructive pulmonary disease. Am J Respir Crit Care Med. 2006; 173(8):858-864.

66. Ciencewicki J, Trivedi S, Kleeberger SR. Oxidants and the pathogenesis of lung diseases. J Allergy Clin Immunol. 2008;122(3):456-468.

67. Hwang NR, Yim S, Kim YM, et al. Oxidative modifications of glyceraldehyde-3-phosphate dehydrogenase play a key role in its multiple cellular functions. Biochem J. 2009;423(2):253-264.
68. Kitagawa H, Yamaoka I, Akimoto C, et al. A reduction state potentiates the glucocorticoid response through receptor protein stabilization. Genes Cells. 2007;12(11):1281-1287.

69. Wright VP, Reiser PJ, Clanton TL. Redox modulation of global phosphatase activity and protein phosphorylation in intact skeletal muscle. J Physiol. 2009;587(23):5767-5781.

70. Tomlinson JE, McMahon AD, Chaudhuri R, Thompson JM, Wood SF, Thomson NC. Efficacy of low and high dose inhaled corticosteroid in smokers versus non-smokers with mild asthma. Thorax. 2005;60(4):282-287.

71. Ito K, Lim S, Caramori G, Chung KF, Barnes PJ, Adcock IM. Cigarette smoking reduces histone deacetylase 2 expression, enhances cytokine expression, and inhibits glucocorticoid actions in alveolar macrophages. FASEB J. 2001;15(6):1110-1112.

72. Rahman I, Marwick J, Kirkham P. Redox modulation of chromatin remodeling: impact on histone acetylation and deacetylation, NFkappaB and pro-inflammatory gene expression. Biochem Pharmacol. 2004;68(6):1255-1267.

73. Marwick JA, Ito K, Adcock IM, Kirkham PA. Oxidative stress and steroid resistance in asthma and COPD: pharmacological manipulation of HDAC-2 as a therapeutic strategy. Expert Opin Ther Targets. 2007;11(6):745-755.

74. Li B, Carey M, Workman JL. The role of chromatin during transcription. Cell. 2007;128(4):707-719.

75. Glass CK, Ogawa S. Combinatorial roles of nuclear receptors in inflammation and immunity. Nat Rev Immunol. 2006;6(1):44-55.

76. Choi JK, Howe LJ. Histone acetylation: truth of consequences? Biochem Cell Biol. 2009;87(1):139-150.

77. Ito K, Yamamura S, Essilfie-Quaye S, et al. Histone deacetylase 2-mediated deacetylation of the glucocorticoid receptor enables NFkappaB suppression. J Exp Med. 2006;203(1):7-13.

78. Marwick JA, Kirkham PA, Stevenson CS, et al. Cigarette smoke alters chromatin remodeling and induces proinflammatory genes in rat lungs. Am J Respir Cell Mol Biol. 2004;31(6):633-642.

79. Meja KK, Rajendrasozhan S, Adenuga D, et al. Curcumin restores corticosteroid function in monocytes exposed to oxidants by maintaining HDAC2. Am J Respir Cell Mol Biol. 2008;39(3):312-323.

80. Ito K, Hanazawa T, Tomita K, Barnes PJ, Adcock IM. Oxidative stress reduces histone deacetylase 2 activity and enhances IL- 8 gene expression: role of tyrosine nitration. Biochem Biophys Res Commun. 2004;315(1):240-245.

81. Osoata GO, Yamamura S, Ito M, et al. Nitration of distinct tyrosine residues causes inactivation of histone deacetylase 2. Biochem Biophys Res Commun. 2009;384(3):366-371.

82. Galasinski SC, Resing KA, Goodrich JA, Ahn NG. Phosphatase inhibition leads to histone deacetylases 1 and 2 phosphorylation and disruption of corepressor interactions. J Biol Chem. 2002;277(22):19618-19626.

83. Rahman I, Adcock IM. Oxidative stress and redox regulation of lung inflammation in COPD. Eur Respir J. 2006;28(1):219-242.

84. Adenuga D, Yao H, March TH, Seagrave J, Rahman I. Histone deacetylase 2 is phosphorylated, ubiquitinated, and degraded by cigarette smoke. Am J Respir Cell Mol Biol. 2009;40(4):464-473.

85. Adenuga D, Rahman I. Protein kinase CK2-mediated phosphorylation of HDAC2 regulates co-repressor formation, deacetylase activity and acetylation of HDAC2 by cigarette smoke and aldehydes. Arch Biochem Biophys. 2010;498(1):62-73.

86. Ito K, Ito M, Elliott WM, et al. Decreased histone deacetylase activity in chronic obstructive pulmonary disease. $N$ Engl J Med. 2005;352(19):1967-1976.

87. Cosio BG, Tsaprouni L, Ito K, Jazrawi E, Adcock IM, Barnes PJ. Theophylline restores histone deacetylase activity and steroid responses in COPD macrophages. J Exp Med. 2004;200(5):689-695.

88. Yang SR, Chida AS, Bauter MR, et al. Cigarette smoke induces proinflammatory cytokine release by activation of NF-kappaB and posttranslational modifications of histone deacetylase in macrophages. Am J Physiol Lung Cell Mol Physiol. 2006;291(1):L46-L57. 
89. Adcock IM, Chung KF, Caramori G, Ito K. Kinase inhibitors and airway inflammation. Euro J Pharmacol. 2006;533(1-3):118-132.

90. Renda T, Baraldo S, Pelaia G, et al. Increased activation of p38 MAPK in COPD. Eur Respir J. 2008;31(1):62-69.

91. Irusen E, Matthews JG, Takahashi A, Barnes PJ, Chung KF, Adcock IM. p38 Mitogen-activated protein kinase-induced glucocorticoid receptor phosphorylation reduces its activity: role in steroid-insensitive asthma. J Allergy Clin Immunol. 2002;109(4):649-657.

92. Bhavsar P, Hew M, Khorasani N, et al. Relative corticosteroid insensitivity of alveolar macrophages in severe asthma compared with non-severe asthma. Thorax. 2008;63(9):784-790.

93. Galliher-Beckley AJ, Cidlowski JA. Emerging roles of glucocorticoid receptor phosphorylation in modulating glucocorticoid hormone action in health and disease. IUBMB Life. 2009;61:979-986.

94. Galliher-Beckley AJ, Williams JG, Collins JB, Cidlowski JA. Glycogen synthase kinase 3beta-mediated serine phosphorylation of the human glucocorticoid receptor redirects gene expression profiles. Mol Cell Biol. 2008;28(24):7309-7322.

95. Barthel A, Klotz LO. Phosphoinositide 3-kinase signaling in the cellular response to oxidative stress. Biol Chem. 2005;386(3): 207-216.

96. Marwick JA, Caramori G, Casolari P, et al. A role for phosphoinositol 3-kinase delta in the impairment of glucocorticoid responsivness in patients with chronic obstructive pulmonary disease. J Allergy Clin Immunol. 2010;125(5):1146-1153.

97. Marwick JA, Stevenson CS, Chung KF, Adcock IM, Kirkham PA. Cigarette smoke exposure alters $\mathrm{mSin} 3 \mathrm{a}$ and Mi-2alpha/beta expression; implications in the control of pro-inflammatory gene transcription and glucocorticoid function. $J$ Inflamm. In press 2010.

98. Evans DJ, Taylor DA, Zetterstrom O, Chung KF, O'Connor BJ, Barnes PJ. A comparison of low-dose inhaled budesonide plus theophylline and high-dose inhaled budesonide for moderate asthma. N Engl J Med. 1997;337(20):1412-1418.

99. Cosio BG, Iglesias A, Rios A, et al. Low-dose theophylline enhances the anti-inflammatory effects of steroids during exacerbations of COPD. Thorax. 2009;64(5):424-429.

100. Marwick JA, Wallis G, Meja K, et al. Oxidative stress modulates theophylline effects on steroid responsiveness. Biochem Biophys Res Commun. 2008;377(3):797-802.

101. Cusack BJ, Dawson GW, Mercer GD, Vestal RE. Cigarette smoking and theophylline metabolism: effects of cimetidine. Clin Pharm Ther. 1985;37(3):330-336.

102. Ito $\mathrm{K}$, Lim S, Caramori $\mathrm{G}$, et al. A molecular mechanism of action of theophylline: induction of histone deacetylase activity to decrease inflammatory gene expression. Proc Nat Acad Sci U S A. 2002;99(13):8921-8926.

103. Ford PA, Durham AL, Russell RE, Gordon F, Adcock IM, Barnes PJ. Treatment effects of low-dose theophylline combined with an inhaled corticosteroid in COPD. Chest. 2010;137(6):1338-1344.

104. Rahman I, Biswas SK, Kirkham PA. Regulation of inflammation and redox signaling by dietary polyphenols. Biochem Pharmacol. 2006;72(11):1439-1452.

105. Rahman I. Dietary polyphenols mediated regulation of oxidative stress and chromatin remodeling in inflammation. Nutr Rev. 2008; 66(Suppl 1):S42-S45.

106. Bengmark S, Mesa M, Gil A. Plant-derived health: the effects of turmeric and curcuminoids. Nut Hosp. 2009;24:273-281.

107. Sasaki T, Irie-Sasaki J, Jones RG, et al. Function of PI3K $\gamma$ in thymocyte development, T cell activation, and neutrophil migration. Science. 2000;287(5455):1040-1046.

108. Hirsch E, Katanaev VL, Garlanda C, et al. Central role for G proteincoupled phosphoinositide 3-kinase $\gamma$ in Inflammation. Science. 2000;287(5455):1049-1053.

109. Okkenhaug K, Bilancio A, Farjot G, et al. Impaired B and T cell antigen receptor signaling in p110delta PI 3-kinase mutant mice. Science. 2002;297(5583):1031-1034.
110. Okkenhaug K, Vanhaesebroeck B. PI3K in lymphocyte development, differentiation and activation. Nat Rev Immunol. 2003;3(4): 317-330.

111. Condliffe AM, Davidson K, Anderson KE, et al. Sequential activation of class IB and class IA PI3K is important for the primed respiratory burst of human but not murine neutrophils. Blood. 2005;106(4):1432-1440.

112. Puri KD, Doggett TA, Douangpanya J, et al. Mechanisms and implications of phosphoinositide 3-kinase delta in promoting neutrophil trafficking into inflamed tissue. Blood. 2004;103(9):3448-3456.

113. Rennard SI, Fogarty C, Kelsen S, et al. The safety and efficacy of infliximab in moderate to severe chronic obstructive pulmonary disease. Am J Respir Crit Care Med. 2007;175(9):926-934.

114. Smith SJ, Fenwick PS, Nicholson AG, et al. Inhibitory effect of p38 mitogen-activated protein kinase inhibitors on cytokine release from human macrophages. Br J Pharmacol. 2006;149(4):393-404.

115. Tudhope SJ, Finney-Hayward TK, Nicholson AG, et al. Different mitogen-activated protein kinase-dependent cytokine responses in cells of the monocyte lineage. J Pharmacol Exp Ther. 2008;324(1): 306-312.

116. Medicherla S, Fitzgerald MF, Spicer D, et al. p38alpha selective mitogen-activated protein kinase inhibitor SD-282 reduces inflammation in a subchronic model of tobacco smoke-induced airway inflammation. J Pharmacol Exp Ther. 2008;324(3):921-929.

117. Williams AS, Issa R, Durham A, et al. Role of p38 mitogen-activated protein kinase in ozone-induced airway hyperresponsiveness and inflammation. Eur J Pharmacol. 2008;600(1-3):117-122.

118. Singh D, Smyth L, Borrill Z, Sweeney L, Tal-Singer R. A randomized, placebo-controlled study of the effects of the p38 MAPK inhibitor SB-681323 on blood biomarkers of inflammation in COPD patients. J Clin Pharmacol. 2010;50(1):94-100.

119. Dambach DM. Potential adverse effects associated with inhibition of p38alpha/beta MAP kinases. Curr Top Med Chem. 2005;5(10):929-939.

120. Meagher LC, Cousin JM, Seckl JR, Haslett C. Opposing effects of glucocorticoids on the rate of apoptosis in neutrophilic and eosinophilic granulocytes. J Immunol. 1996;156(11):4422-4428.

121. Serhan CN, Savill J. Resolution of inflammation: the beginning programs the end. Nat Immunol. 2005;6(12):1191-1197.

122. Savill JS, Wyllie AH, Henson JE, Walport MJ, Henson PM, Haslett C. Macrophage phagocytosis of aging neutrophils in inflammation. Programmed cell death in the neutrophil leads to its recognition by macrophages. J Clin Invest. 1989;83(3):865-875.

123. Rossi AG, Sawatzky DA, Walker A, et al. Cyclin-dependent kinase inhibitors enhance the resolution of inflammation by promoting inflammatory cell apoptosis. Nat Med. 2006;12(9):1056-1064.

124. Michlewska S, Dransfield I, Megson IL, Rossi AG. Macrophage phagocytosis of apoptotic neutrophils is critically regulated by the opposing actions of pro-inflammatory and anti-inflammatory agents: key role for TNF- $\alpha$. FASEB J. 2009;23(3):844-854.

125. Fadok VA, Bratton DL, Konowal A, Freed PW, Westcott JY, Henson PM. Macrophages that have ingested apoptotic cells in vitro inhibit proinflammatory cytokine production through autocrine/ paracrine mechanisms involving TGF-beta, PGE2, and PAF. J Clin Invest. 1998;101(4):890-898.

126. Voll RE, Herrmann M, Roth EA, Stach C, Kalden JR, Girkontaite I. Immunosuppressive effects of apoptotic cells. Nature. 1997;390(6658):350-351.

127. Kirkham PA, Spooner G, Rahman I, Rossi AG. Macrophage phagocytosis of apoptotic neutrophils is compromised by matrix proteins modified by cigarette smoke and lipid peroxidation products. Biochem Biophys Res Commun. 2004;318(1):32-37.

128. Hodge S, Hodge G, Ahern J, Jersmann H, Holmes M, Reynolds PN. Smoking alters alveolar macrophage recognition and phagocytic ability: implications in chronic obstructive pulmonary disease. Am J Respir Cell Mol Biol. 2007;37(6):748-755. 
129. Pinho V, Souza DG, Barsante MM, et al. Phosphoinositide-3 kinases critically regulate the recruitment and survival of eosinophils in vivo: importance for the resolution of allergic inflammation. J Leukoc Biol. 2005;77(5):800-810.

130. Leverrier Y, Okkenhaug K, Sawyer C, Bilancio A, Vanhaesebroeck B, Ridley AJ. Class I phosphoinositide 3-kinase p110beta is required for apoptotic cell and Fcgamma receptor-mediated phagocytosis by macrophages. J Biol Chem. 2003;278(40):38437-38442.
131. Schwab JM, Chiang N, Arita M, Serhan CN. Resolvin E1 and protectin D1 activate inflammation-resolution programmes. Nature. 2007;447(7146):869-874.

International Journal of COPD

\section{Publish your work in this journal}

The International Journal of COPD is an international, peer-reviewed journal of therapeutics and pharmacology focusing on concise rapid reporting of clinical studies and reviews in COPD. Special focus is given to the pathophysiological processes underlying the disease, intervention programs, patient focused education, and self management protocols.

\section{Dovepress}

This journal is indexed on PubMed Central, MedLine and CAS. The manuscript management system is completely online and includes a very quick and fair peer-review system, which is all easy to use. Visit http://www.dovepress.com/testimonials.php to read real quotes from published authors.

Submit your manuscript here: http://www.dovepress.com/international-journal-of-copd-journal 